\title{
A LA JUVENTUD ARGENTINA DE CÓRDOBA A LOS HOMBRES LIBRES DE SUDAMÉRICA
}

\author{
(Manifiesto del 21 de junio de 1918.)
}

Hombres de una República libre, acabamos de romper la última cadena que, en pleno siglo XX, nos ataba a la antigua dominación monárquica y monástica. Hemos resuelto llamar a todas las cosas por el nombre que tienen. Córdoba se redime. Desde hoy contamos para el país una vergüenza menos y una libertad más. Los dolores que quedan son las libertades que faltan. Creemos no equivocarnos, las resonancias del corazón nos lo advierten: estamos pisando sobre una revolución, estamos viviendo una hora americana.

La rebeldía estalla ahora en Córdoba y es violenta porque aquí los tiranos se habían ensoberbecido y era necesario borrar para siempre el recuerdo de los contrarrevolucionarios de Mayo. Las universidades han sido hasta aquí el refugio secular de los mediocres, la renta de los ignorantes, la hospitalización segura de los inválidos y — lo que es peor aún — el lugar en donde todas las formas de tiranizar y de insensibilizar hallaron la cátedra que las dictara. Las universidades han llegado a ser así fiel reflejo de estas sociedades decadentes que se empeñan en ofrecer el triste espectáculo de una inmovilidad senil. Por eso es que la ciencia frente a estas casas mudas y cerradas, pasa silenciosa o entra mutilada y grotesca al servicio burocrático. Cuando en un rapto fugaz abre sus puertas a los altos espíritus es para arrepentirse luego y hacerles imposible la vida en su recinto. Por eso es que, dentro de semejante régimen, las fuerzas naturales llevan a mediocrizar la enseñanza, y el ensanchamiento vital de los organismos universitarios no es el fruto del desarrollo orgánico, sino el aliento de la periodicidad revolucionaria

Nuestro régimen universitario — aún el más reciente_ es anacrónico. Está fundado sobre una especie de derecho divino; el derecho divino del profesorado universitario. Se crea a sí mismo. En él nace y en él muere. Mantiene un alejamiento olímpico. La federación universitaria de Córdoba se alza para luchar contra este régimen y entiende que en ello le va la vida. Reclama un gobierno estrictamente democrático y sostiene que el demos universitario, la soberanía, el derecho a darse el gobierno propio radica principalmente en los estudiantes. El concepto de autoridad que corresponde y acompaña a un director o a un maestro en un hogar de estudiantes universitarios no puede apoyarse en la fuerza de disciplinas extrañas a la sustancia misma de los estudios. La autoridad, en un hogar de estudiantes, no se ejercita mandando, sino sugiriendo y amando: enseñando.

Si no existe una vinculación espiritual entre el que enseña y el que aprende, toda enseñanza es hostil y por consiguiente infecunda. Toda la educación es una larga obra de amor a los que aprenden. Fundar la garantía de una paz fecunda en el artículo conminatorio de un reglamento o de un estatuto es, en todo caso, amparar un régimen cuartelario, pero no una labor de ciencia. Mantener la actual relación de gobernantes a gobernados es agitar el fermento de futuros trastornos. Las almas de los jóvenes deben 
ser movidas por fuerzas espirituales. Los gastados resortes de la autoridad que emana de la fuerza no se avienen con lo que reclaman el sentimiento y el concepto moderno de las universidades. El chasquido del látigo sólo puede rubricar el silencio de los inconscientes o de los cobardes. La única actitud silenciosa, que cabe en un instituto de ciencia es la del que escucha una verdad o la del que experimenta para crearla o comprobarla.

Por eso queremos arrancar de raíz en el organismo universitario el arcaico y bárbaro concepto de autoridad que en estas casas de estudio es un baluarte de absurda tiranía y sólo sirve para proteger criminalmente la falsa dignidad y la falsa competencia. Ahora advertimos que la reciente reforma, sinceramente liberal, aportada a la Universidad de Córdoba por el doctor José Nicolás Matienzo, sólo ha venido a probar que el mal era más afligente de lo que imaginábamos y que los antiguos privilegios disimulaban un estado de avanzada descomposición. La reforma Matienzo no ha inaugurado una democracia universitaria; ha sancionado el predominio de una casta de profesores. Los intereses creados en torno de los mediocres han encontrado en ella un inesperado apoyo. Se nos acusa ahora de insurrectos en nombre de un orden que no discutimos, pero que nada tiene que hacer con nosotros. Si ello es así, si en nombre del orden se nos quiere seguir burlando y embruteciendo, proclamamos bien alto el derecho sagrado a la insurrección. Entonces la única puerta que nos queda abierta a la esperanza es el destino heroico de la juventud. El sacrificio es nuestro mejor estímulo; la redención espiritual de las juventudes americanas nuestra única recompensa, pues sabemos que nuestras verdades lo son -y dolorosas — de todo el continente. ¿Que en nuestro país una ley — se dice_- la ley de Avellaneda, se opone a nuestros anhelos? Pues a reformar la ley, que nuestra salud moral lo está exigiendo.

La juventud vive siempre en trance de heroísmo. Es desinteresada, es pura. No ha tenido tiempo aún de contaminarse. No se equivoca nunca en la elección de sus propios maestros. Ante los jóvenes no se hace mérito adulando o comprando. Hay que dejar que ellos mismos elijan sus maestros y directores, seguros de que el acierto ha de coronar sus determinaciones. En adelante, sólo podrán ser maestros en la república universitaria los verdaderos constructores de almas, los creadores de verdad, de belleza y de bien.

La juventud universitaria de Córdoba cree que ha llegado la hora de plantear este grave problema a la consideración del país y de sus hombres representativos. Los sucesos acaecidos recientemente en la Universidad de Córdoba, con motivo de la elección rectoral, aclaran singularmente nuestra razón en la manera de apreciar el conflicto universitario. La federación universitaria de Córdoba cree que debe hacer conocer al país y a América las circunstancias de orden moral y jurídico que invalidan el acto electoral verificado el 15 de junio. Al confesar los ideales y principios que mueven a la juventud en esta hora única de su vida, quiere referir los aspectos locales del conflicto y levantar bien alta la llama que está quemando el viejo reducto de la opresión clerical. En la Universidad Nacional de Córdoba y en esta ciudad no se han presenciado desórdenes; se ha contemplado y se contempla el nacimiento de una verdadera revolución que ha de agrupar bien pronto bajo su bandera a todos los hombres libres del continente. Referiremos los sucesos para que se vea cuánta razón nos asistía y cuánta vergüenza nos sacó a la 
cara la cobardía y la perfidia de los reaccionarios. Los actos de violencia, de los cuales nos responsabilizamos íntegramente, se cumplían como en el ejercicio de puras ideas. Volteamos lo que representaba un alzamiento anacrónico y lo hicimos para poder levantar siquiera el corazón sobre esas ruinas. Aquellos representan también la medida de nuestra indignación en presencia de la miseria moral, de la simulación y del engaño artero que pretendía filtrarse con las apariencias de la legalidad. El sentido moral estaba obscurecido en las clases dirigentes por un fariseísmo tradicional y por una pavorosa indigencia de ideales.

El espectáculo que ofrecía la asamblea universitaria era repugnante. Grupos de amorales deseosos de captarse la buena voluntad del futuro rector exploraban los contornos en el primer escrutinio, para inclinarse luego al bando que parecía asegurar 120 el triunfo, sin recordar la adhesión públicamente empeñada, el compromiso de honor contraído por los intereses de la universidad. Otros —los más- en nombre del sentimiento religioso y bajo la advocación de la Compañía de Jesús, exhortaban a la traición y al pronunciamiento subalterno. (¡Curiosa religión que enseña a menospreciar el honor y deprimir la personalidad! ¡Religión para vencidos o para esclavos!). Se había obtenido una reforma liberal mediante el sacrificio heroico de una juventud. Se creía haber conquistado una garantía y de la garantía se apoderaban los únicos enemigos de la reforma. En la sombra los jesuitas habían preparado el triunfo de una profunda inmoralidad. Consentirla habría comportado otra traición. A la burla respondimos con la revolu- ción. La mayoría expresaba la suma de la represión, de la ignorancia y del vicio. Entonces dimos la única lección que cumplía y espantamos para siempre la amenaza del dominio clerical.

La sanción moral es nuestra. El derecho también. Aquellos pudieron obtener la sanción jurídica, empotrarse en la ley. No se lo permitimos. Antes de que la iniquidad fuera un acto jurídico, irrevocable y completo, nos apoderamos del salón de actos y arrojamos a la canalla, sólo entonces amedrentada, a la vera de los claustros. Que esto es cierto, lo patentiza el hecho de haber, a continuación, sesionado en el propio salón de actos la federación universitaria y de haber firmado mil estudiantes sobre el mismo pupitre rectoral, la declaración de huelga indefinida.

En efecto, los estatutos reformados disponen que la elección de rector terminará en una sola sesión, proclamándose inmediatamente el resultado, previa lectura de cada una de las boletas y aprobación del acta respectiva. Afirmamos, sin temor de ser rectificados, que las boletas no fueron leídas, que el acta no fue aprobada, que el rector no fue proclamado, y que, por consiguiente, para la ley, aún no existe rector de esta universidad.

La juventud universitaria de Córdoba afirma que jamás hizo cuestión de nombres ni de empleos. Se levantó contra un régimen administrativo, contra un método docente, contra un concepto de autoridad. Las funciones públicas se ejercitaban en beneficio de determinadas camarillas. No se reformaban ni planes ni reglamentos por temor de que alguien en los cambios pudiera perder su empleo. 
La consigna de «hoy para ti, mañana para mí», corría de boca en boca y asumía la preeminencia de estatuto universitario. Los métodos docentes estaban viciados de un estrecho dogmatismo, contribuyendo a mantener a la universidad apartada de la ciencia y de las disciplinas modernas. Las elecciones, encerradas en la repetición interminable de viejos textos, amparaban el espíritu de rutina y de sumisión. Los cuerpos universitarios, celosos guardianes de los dogmas, trataban de mantener en clausura a la juventud, creyendo que la conspiración del silencio puede ser ejercitada en contra de la ciencia. Fue entonces cuando la oscura universidad mediterránea cerró sus puertas a Ferri, a Ferrero, a Palacios y a otros, ante el temor de que fuera perturbada su plácida ignorancia. Hicimos entonces una santa revolución y el régimen cayó a nuestros golpes.

Creímos honradamente que nuestro esfuerzo había creado algo nuevo, que por lo menos la elevación de nuestros ideales merecía algún respeto. Asombrados, contemplamos entonces cómo se coaligaban para arrebatar nuestra conquista los más crudos reaccionarios. No podemos dejar librada nuestra suerte a la tiranía de una secta religiosa, ni al juego de intereses egoístas. A ellos se nos quiere sacrificar. El que se titula rector de la Universidad de San Carlos ha dicho su primera palabra: «Prefiero antes de renunciar que quede el tendal de cadáveres de los estudiantes». Palabras llenas de piedad y de amor, de respeto reverencioso a la disciplina; palabras dignas del jefe de una casa de altos estudios. No invoca ideales ni propósitos de acción cultural.
Se siente custodiado por la fuerza y se alza soberbio y amenazador. ¡Armoniosa lección que acaba de dar a la juventud el primer ciudadano de una democracia universitaria! Recojamos la lección, compañeros de toda América; acaso tenga el sentido de un presagio glorioso, la virtud de un llamamiento a la lucha suprema por la libertad; ella nos muestra el verdadero carácter de la autoridad universitaria, tiránica y obcecada, que ve en cada petición un agravio y en cada pensamiento una semilla de rebelión.

La juventud ya no pide. Exige que se le reconozca el derecho a exteriorizar ese pensamiento propio en los cuerpos universitarios por medio de sus representantes. Está cansada de soportar a los tiranos. Si ha sido capaz de realizar una revolución en las conciencias, no puede desconocérsele la capacidad de intervenir en el gobierno de su propia casa.

La juventud universitaria de Córdoba, por intermedio de su federación, saluda a los compañeros de América toda y les incita a colaborar en la obra de libertad que inicia.

Firmado: Enrique F. Barros, Ismael C. Bordabehére, Horacio Valdés,presidentes. - Gumersindo Sayago. -Alfredo Castellanos. - Luis M. Méndez. - Jorge L. Bazante. - Ceferino Garzón Maceda. - Julio Molina. - Carlos Suárez Pinto. - Emilio R. Biagosch. - Angel J. Nigro. - Natalio J. Saibene. - Antonio Medina Allende. - Ernesto Garzón. 